\title{
Molecular Approaches for Isolation of Shigella Species from Culture Negative Diarrheal Samples: A Hospital Based Study in Bangladesh
}

\author{
Tarana Sharmin 1, *, Mahmuda Akter², Atanu Banik², Ahmed Faisal Sumit², Tasnim Ahmed², \\ Shahin Mahmud ${ }^{3}$, Ashraf Hossain Talukder ${ }^{3}$, Kaisar Ali Talukder ${ }^{3}$ \\ ${ }^{1}$ Department of Genetic Engineering and Biotechnology, University of Dhaka. Dhaka, Bangladesh \\ ${ }^{2}$ Laboratory Science and Services Division, International Center for Diarrheal Disease Research, Bangladesh .Department of Genetic \\ Engineering and Biotechnology, University of Dhaka, Dhaka, Bangladesh \\ ${ }^{3}$ Department of Biotechnology and Genetic Engineering, Mawlana Bhashani Science and Technology University, Santosh, Tangail
}

Email address:

tarana.sharmin@du.ac.bd (T. Sharmin)

${ }^{*}$ Corresponding author

\section{To cite this article:}

Tarana Sharmin, Mahmuda Akter, Atanu Banik, Ahmed Faisal Sumit, Tasnim Ahmed, Shahin Mahmud, Ashraf Hossain Talukder, Kaisar Ali Talukder. Molecular Approaches for Isolation of Shigella Species from Culture Negative Diarrheal Samples: A Hospital Based Study in Bangladesh. American Journal of Biological and Environmental Statistics. Vol. 7, No. 2, 2021, pp. 39-43.

doi: 10.11648/j.ajbes.20210702.11

Received: April 20, 2021; Accepted: May 13, 2021; Published: May 31, 2021

\begin{abstract}
Diarrhoeal infection is defined as a significant reason of morbidity as well as mortality all over the world. Isolation of Shigella, the most significant etiological agents of diarrhea in developing countries, was missing occasionally when patients feces are cultured by conventional procedures. The collected 200 samples from hospitalized diarrhoeal patients in Tangail district, Bangladesh during 2010-2011, Shigella were isolated from 24 (12\%) samples utilizing conventional culture methods. Among176 culture negative stool samples,ipa $\mathrm{H}$ gene, specific marker to identify Shigella species was detected from $14(8 \%)$ by PCR. Furthermore, these samples which possess the ipa $\mathrm{H}$ gene were cultured and identified as Shigella-like organism (s) by utilizing various phenotypic as well as molecular tools. Of 24 Shigella spp. which was identified using conventional culture methods, S. flexneri were dominant $41.7 \%$, followed by $S$. boydii $29.2 \%$, S. sonnei $25 \%$, and $S$. dysenteriae $4.2 \%$. Among 14 of 176 culture negative ipa $\mathrm{H}$ positive samples, 7 were identified as Shigella sspp., of which, 3 were $S$. flexneri, 1 was $S$. boydii, 2 were $S$. sonnei and 1 identified as a novel group of $S$. dysenteriae designated as KIVI 156. Additionally, all Shigella strains were resistant to ampicillin, sulfamethaxol-trimethoprime and were susceptible to ciprofloxacin and mecillinam. This study demonstrated that the conventional culture method cannot be referred as an adequate method to focus the actual disease burden caused by Shigella.
\end{abstract}

Keywords: Diarrhoea, Shigellosis, Polymerase Chain Reaction (PCR)

\section{Introduction}

Shigella species are referred to be the causative agent for shigellosis. This disorder has emerged as an indispensable public health crisis in countries like Bangladesh where hygiene is limited. In every year, around 165 million cases of reports demonstrating the Shigella infection have been investigated all over the world [1]. Furthermore, it appears that Shigella spp. frequently escape diagnosis by established culture procedure [2]. In addition, an extensive variety of antigenic specificity exists among various Shigella species [3]. For these consequences, isolation by conventional culture methods has always been suspected. Previous studies demonstrated that no Shigella spp. were isolated from $42 \%$ clinically Shigellosis patients [4]. Moreover, numerous plasmid-encoded virulence genes like invasion antigen loci (ial) and invasion plasmid antigen $\mathrm{H}$ gene (ipa $\mathrm{H}$ ), can be utilized for identification of Shigella by Polymerase chain reaction (PCR). The gene ial is located on the large virulence 
plasmid (140 MDa) while the ipa $\mathrm{H}$ is encoded multiple copies of the plasmid as well as the chromosome [5]. This study was designed to analyze the undetected cases (clinically shigellosis cases, but Shigella was not detected by conventional culture methods) by using molecular fingerprinting tools, PCR to identify the causative agents, especially Shigella species and their prevalence, which will be conducted for proper treatment as well as further improved prevention. Therefore, the endeavor of this investigation was to identify Shigella and Shigella-like organism (s) by PCR using ipa $\mathrm{H}$ gene from the stools of clinically Shigellosis patients from whom no Shigella species were detected by conventional culture methods.

\section{Materials and Methods}

A total of 200 stool samples was collected from diarrheal patients irrespective of age, sex and disease severity attended in the Health and Demographic Surveillance System (DSS) area in Kumudini Hospital, Mirzapur, the field site of icddr,b between December 2010 and February 2011. Of these samples, Shigella species were isolated from $24(12 \%)$ samples.

\subsection{Sampling Procedure}

At least $3 \mathrm{ml} /$ grams of fresh stool sample was collected between December 2010 and February 2011 into sterile, screw-capped containers containing Carry-Blair media maintaining cool temperature. All the specimens were cultured on MacConkey and Salmonella-Shigella (SS) Agar (Oxoid,UK) media plate within 6 hours of collection and incubated overnight at $37^{\circ} \mathrm{C}$. Furthermore, non-lactose fermenting Shigella like colonies were isolated and characterized using standard methods. All these 200 samples were further enriched in Trypticase Soy Broth (TSB) (Oxoid,UK) with $0.3 \%$ yeast extract (YE) for overnight at $37^{\circ} \mathrm{C}$. Of these enriched broth cultures from whom no Shigella species could be detected,were further administered to detect the presence of Shigella species by PCR using ipa $\mathrm{H}$ gene. Moreover, ipa $\mathrm{H}$ positive samples were further analyzed to detect the presence of Shigella species by using different phenotypic and molecular tools [6].

\subsection{Strains}

YSH6000, S. flexneri 2a and an Escherichia coli strain (ATCC 25922) susceptible to all antibiotics were used as positive and negative controls, respectively, to test for detection of ipa $\mathrm{H}$ gene and the antibiotic susceptibility test [6].

\subsection{Categorization of Biochemical Features}

The biochemical characters of the strains were investigated by standard traditional procedure [7]. In brief, non-lactose fermenting strains characteristically resembling Shigella were separated from other nonlactose-fermenting strains by inoculating into Kligler's iron agar for characteristic reaction to differentiate organisms by demonstrating hydrogen sulfide production and the fermentation of dextrose and lactose. The motility indole urea test was administered to differentiate the organisms on the basis of motility, urease and indole production and Cimon citrate for citrate utilization according to the procedure described elsewhere. After incubation for $18-24 \mathrm{~h}$ at $37^{\circ} \mathrm{C}$, the media were analyzed for the distinctive features of Shigella infection.

\subsection{Investigation of ipaH Gene by PCR}

Exploration of the ipa $H$ gene was performed by amplification by PCR with primers according to previously described procedures [8]. Primers (forward, 5'TGGAAAAACTCAGTGCCTCT3'; reverse, 5' CCAGTCCGTAAATTCATTCT3') were utilized using an Oligo 1000 DNA synthesizer (Beckman), available in our laboratory at ICDDR, B. PCR reactions were carried out in a DNA thermal cycler (model 480; Perkin-Elmer Cetus, Emeryville, USA). All PCR reactions followed the same fundamental procedures: $94^{\circ} \mathrm{C}$ for $90 \mathrm{sec}$ followed by 30 cycles of $45 \mathrm{sec}$ at $94^{\circ} \mathrm{C}$, at $T_{\text {annealing }}$ at $60^{\circ} \mathrm{C}$ for $45 \mathrm{sec}$ and $T i_{\text {elongate }}$ at $72^{\circ} \mathrm{C}$ for $90 \mathrm{sec}$, where $T_{\text {annealing }}$ was the specific annealing temperature and $T i_{\text {elongate }}$ was the specific elongation time for each reaction, with a final extension at $72^{\circ} \mathrm{C}$ for 3 min. DNA obtained from E. coli ATCC 25922 and YSH6000, S. flexneri 2a strains were used as negative and positive controls. Every isolate containing one single colony was suspended in $25 \mu \mathrm{l}$ of reaction mixer containing $3.0 \mu \mathrm{l}$ of $10 \mathrm{x}$ PCR master mix, $1.5 \mu 1$ of $50 \mathrm{mM}$ $\mathrm{MgCl}_{2}, 2.5 \mu \mathrm{l}$ of $2.5 \mathrm{mM} \mathrm{dNTP}, 0.5 \mu \mathrm{l}$ of primer (forward and reverse) together with $0.2 \mu 1$ of Taq DNA polymerase $(5 \mathrm{U} / \mu \mathrm{l})$. Amplified PCR products were taken into horizontal gel electrophoresis in $1 \%$ agarose gel in TBE (Tris-borate EDTA) buffer at room temperature at 100 volts $(50 \mathrm{~mA})$ for $1 \mathrm{~h}$. Briefly, $10 \mu \mathrm{l}$ of amplified DNA for each sample was mixed with $1 \mu \mathrm{l}$ of tracking dye and loaded into an individual well of the gel (approx. $5 \mathrm{~mm}$ thick). Obtained DNA bands were analyzed by staining the gel with ethidium bromide $(0.5 \mu \mathrm{g} / \mathrm{ml})$ for 30 minutes at room temperature and photographs were taken. In order to measure the molecular size of the amplified products, $1 \mathrm{~kb}$ DNA size standard (Bio-Rad) was utilized as a marker.

\subsection{Investigation of ipaH Positive Colony by Colony Patch PCR Technique}

176 enriched broth cultures from whom no Shigella species could be detected were further used to detect presence of Shigella species by PCR using ipa $\mathrm{H}$ gene following the procedure described elsewhere [8]. Of them, $i p a \mathrm{H}$ positive samples were further analyzed to detect presence of Shigella species by using various phenotypic and molecular tools [6]. Different non-lactose fermenting single colonies grown in MacConkey agar plate from ipaH positive broth to create a grid pattern of 36 colonies $(6 \times 6)$ using colony patch technique. The grids were marked off on the bottom of the plate with equally spaced vertical and horizontal lines. The resulting numbered squares 
demonstrated the identification of individual colonies. The overnight incubation was carried out with the media plates at $37^{\circ} \mathrm{C}$. This method is significant as well as advantageous as it permits a relatively large number of colonies to be screened simultaneously. In this technique, PCR reactions were condensed into 20 by taking the colonies per row and per column in $5 \mathrm{ml}$ sterile distilled water. Additionally, DNA extraction was carried out by boiling the suspensions for 10 min and $5 \mu \mathrm{l}$ of the supernatant was utilized in the PCR reactions. However, the positive colonies were further confirmed by biochemical, serological and API 20E test (bio Mérieux).

\subsection{Analytical Profile Index (API 20E)}

The API 20E strips comprise of 20 Microtubes which contain dehydrated substrates. These tubes were inoculated with a bacterial suspension that reconstitutes the media. In the course of incubation, color changes occur due to the metabolic reactions that are either spontaneous or exposed by the adding up of reagents. The reactions were further investigated in accordance to the reading table. Finally, the detection is obtained by referring to the analytical profile index.

\subsection{Serotyping}

Biochemically identified Shigella species were serologically confirmed by agglutination reaction with commercially available polyvalent somatic (O) antigen grouping sera, mentioned by testing with monovalent antisera for specific serotype identification (antisera from Denka Seiken, Co. Ltd, Japan). Isolates were sub-cultured on MacConkey agar (Oxoid, UK) plates and after the incubation for overnight, serological reaction tests were performed by the agglutination reaction carried out in the glass slides [6]. These strains were then tested with antiserum raised in rabbits against a heat-killed suspension of the selected strains, a novel group of $S$. dysenteriae designated as KIVI 162 [9] and the other one KIVI 156. Antisera were prepared according to the protocol [10].

\subsection{Investigation of Susceptibility Testing of Antimicrobial Agents}

The tested susceptible strains to the antimicrobial agents were further investigated by the disk diffusion methodswith commercial antimicrobial disks (Oxoid, Basingstoke, United Kingdom) [11]. The antibiotic disks administered in this investigation were ampicillin (Amp)(10mg), mecillinam (Mec) (25mg),nalidixic acid (Nal) (30mg), sulfamethaxol trimethoprim (Sxt) (25mg), and ciprofloxacin (Cip) (5mg). E. coli ATCC 25922 and Staphylococcus aureus ATCC 25923 were administered as control strains for the investigation of susceptibility testing.

\section{Results}

About 200 stool samples were collected between December 2010 and February 2011, whereas Shigella spp. were isolated from 24 samples $(12 \%)$ by conventional culture methods. All these 24 Shigella spp. were also ipa $\mathrm{H}$ positive. No Shigella species were isolated from the rest $88 \%(n=176)$ of these 200 stool samples by conventional culture methods. These 176 samples were enriched to test for the existence of $i p a \mathrm{H}$ gene by PCR. Of them, $14(8 \%)$ of 176 samples were positive for $i p a \mathrm{H}$, which is specific for Shigella and EIEC. These $14 i p a \mathrm{H}$ positive samples were further analyzed for the detection of specific ipa $\mathrm{H}$ positive Shigella-like colonies (non-lactose fermenting colonies) by colony patch technique using PCR (Figure 1).

\section{$\begin{array}{lllllllllllllllllll}1 & 2 & 3 & 4 & 5 & 6 & 7 & 8 & 9 & 10 & 11 & 12 & 13 & 14 & 15 & 16 & 17 & 18 & 19\end{array}$}

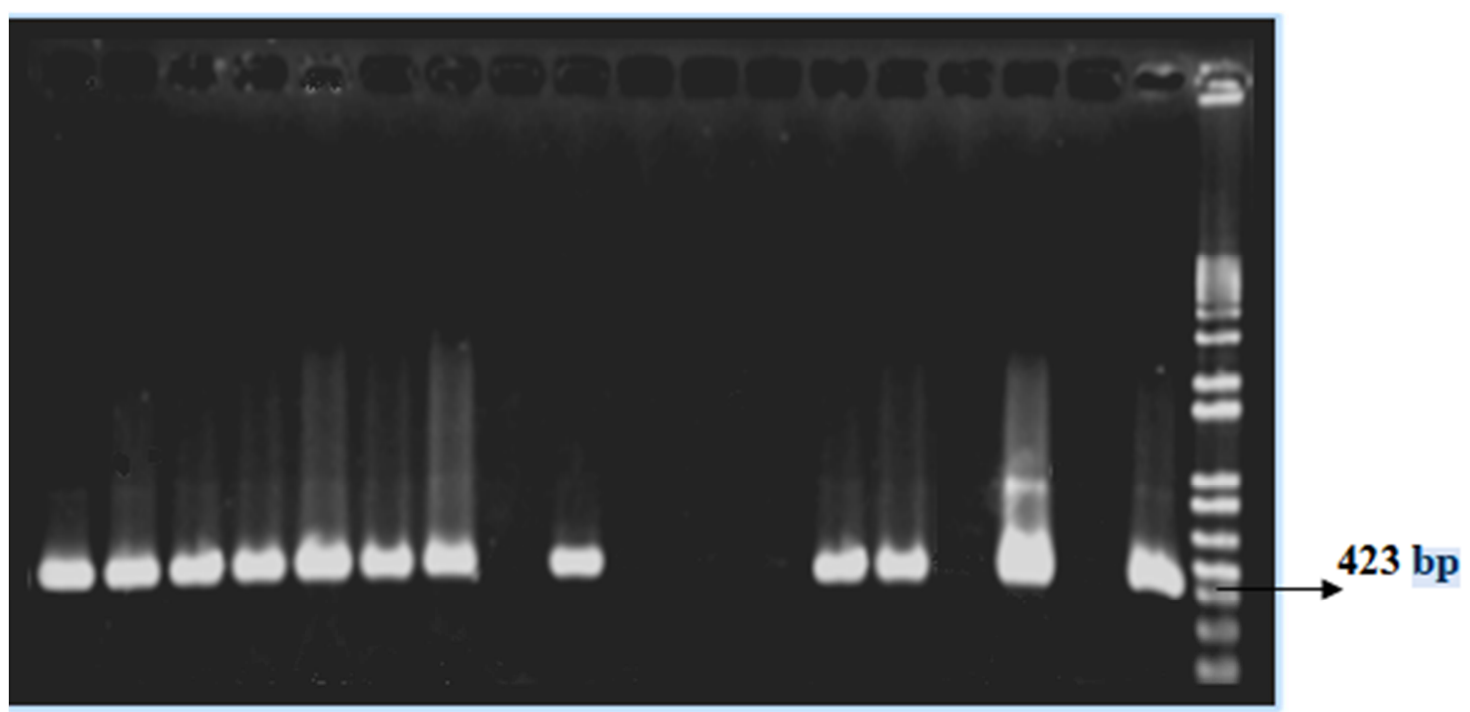

Figure 1. PCR analysis of broth culture of virulence gene (ipaH). Products of PCR assay for the ipaH gene are shown. Lanes 1 through 16 shows the products of enriched broth. Lane 17 represents negative control, 18 shows positive control and 19 shows 1 Kb plus DNA ladder. 


\subsection{Plasmid Profile Analysis}

Heterogenous plasmid profile was found in all of these culture negative ipa $\mathrm{H}$ positive samples. (Figure 2)

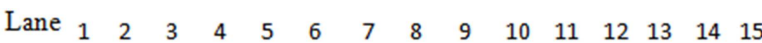

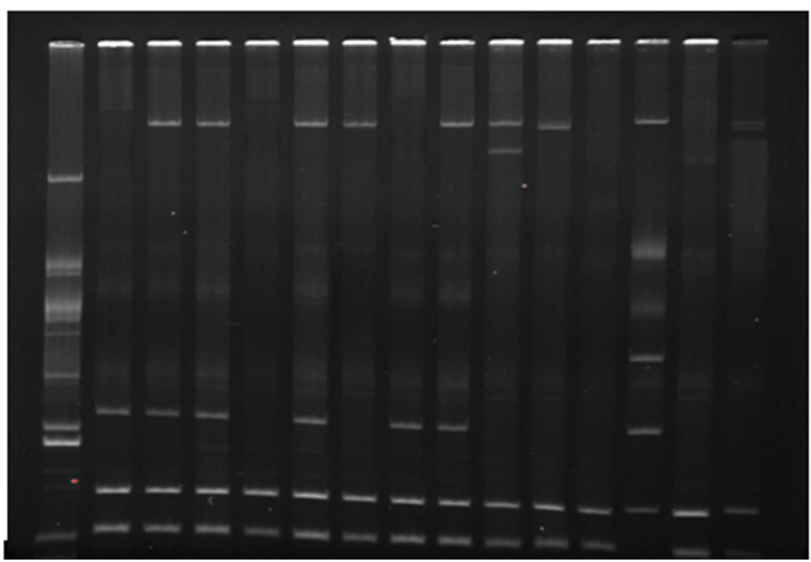

Figure 2. Agarose gel electrophoresis of plasmid DNA showing a representative plasmid pattern. Lanes: $1=V 517$ (Marker), $15=$ PDK9 (Marker)

\subsection{Prevalence of Shigella from ipaH Positive Culture Negative Stool Sample}

About 14 ipa $\mathrm{H}$ positive samples, 6 (42.86\%) were identified as Shigella and $1(7.14 \%)$ as SLOs (Table 1) and no Shigella were isolated from the rest 7 (50\%). Of Shigella spp., 3were identified as $S$. flexneri, 1 was as $S$. boydii, 2 were as $S$. sonnei and the other one SLO could not be serotyped referring the existing serotyping methods. This strain was then reacted with antiserum raised in rabbits against a heat-killed suspension of a representative strain, a novel group of $S$. dysenteriae designated as KIVI 156.

\subsection{Investigation of Biochemical Properties}

All isolated strains demonstrated biochemical reactions resembles Shigella species (Table 1). They were oxidase as well as catalase-negative, and did not ferment D-mannitol, sucrose, lactose, rhamnose, raffinose, xylose, trehalose or dulcitol. All strains utilized arginine and were lysine- and ornithine-negative. API $20 \mathrm{E}$ tests identified all isolates as Shigella species. (Table 1)

Table 1. Biochemical characteristics of representative ipaH positive strains isolated from enriched stool samples.

\begin{tabular}{|c|c|c|c|c|c|c|c|c|c|c|}
\hline \multirow{2}{*}{ Strain ID } & \multicolumn{4}{|c|}{ KIA } & \multicolumn{3}{|c|}{ MIU } & \multirow{2}{*}{ Citrate } & \multirow{2}{*}{ Organism (Presumptive identified) } & \multirow{2}{*}{ Confirmed by Serology } \\
\hline & $\mathbf{S}$ & B & Gas & $\mathrm{H}_{2} \mathrm{~S}$ & $\mathbf{M}$ & $\mathbf{I}$ & $\mathbf{U}$ & & & \\
\hline KH-1351 & $\mathrm{K}$ & A & - & - & - & - & - & - & Shigella spp. & S. flexneri2a \\
\hline KH-1410 & $\mathrm{K}$ & A & - & - & - & - & - & - & Shigella sp. (SLO) & S. dysenteriaeKIVI 156 \\
\hline КН-1489 & $\mathrm{K}$ & A & - & - & - & - & - & - & Shigella spp. & S. flexneri $1 \mathrm{~b}$ \\
\hline КH-1569 & $\mathrm{K}$ & A & - & - & - & - & - & - & Shigella spp. & S. flexneri2a \\
\hline KH-1662 & K & A & - & - & - & - & - & - & Shigella spp. & S. sonnei \\
\hline KH-1783 & $\mathrm{K}$ & A & - & - & - & - & - & - & Shigella spp. & S. sonnei \\
\hline
\end{tabular}

Note: $\mathrm{M}=$ Motility, I=Indole, $\mathrm{U}=$ Urea.

\subsection{Antibiotic Susceptibility Test}

All 7 strains of Shigella were susceptible to ciprofloxacin and mecillam, both of them were commonly administered for treating shigellosis, each strains were resistant to ampicillin and sulfamethaxol trimethoprim (Table 2).

Table 2. Antibiotic susceptibility pattern of Shigella species isolated from ipaH from enriched stool samples.

\begin{tabular}{lll}
\hline Strain ID & Serotype & Antibiotic susceptibility pattern $^{\mathrm{r}}$ \\
\hline $\mathrm{KH}-1351$ & S. flexneri2a & $\mathrm{Sxt}^{\mathrm{r}}, \mathrm{Nal}^{\mathrm{r}}, \mathrm{Amp}^{\mathrm{r}}, \mathrm{Cip}^{\mathrm{s}}, \mathrm{Mec}^{\mathrm{s}}$ \\
$\mathrm{KH}-1410$ & S.dysenteriaeKIVI156 & $\mathrm{Sxt}^{\mathrm{r}}, \mathrm{Nal}^{\mathrm{s}}, \mathrm{Amp}^{\mathrm{r}}{ }^{\mathrm{r}} \mathrm{Cip}^{\mathrm{s}}, \mathrm{Mec}^{\mathrm{s}}$ \\
$\mathrm{KH}-1489$ & S. flexnerilb & $\mathrm{Sxt}^{\mathrm{r}}, \mathrm{Nal}^{\mathrm{r}}, \mathrm{Amp}^{\mathrm{r}}, \mathrm{Cip}^{\mathrm{s}}, \mathrm{Mec}^{\mathrm{s}}$ \\
$\mathrm{KH}-1569$ & S.flexneri2a & $\mathrm{Sxt}^{\mathrm{s}}, \mathrm{Nal}^{\mathrm{r}}, \mathrm{Amp}^{\mathrm{r}}, \mathrm{Cip}^{\mathrm{s}}, \mathrm{Mec}^{\mathrm{s}}$ \\
$\mathrm{KH}-1662$ & S. sonnei & $\mathrm{Sxt}^{\mathrm{r}}, \mathrm{Nal}^{\mathrm{r}}, \mathrm{Amp}^{\mathrm{r}}, \mathrm{Cip}^{\mathrm{s}}, \mathrm{Mec}^{\mathrm{s}}$ \\
$\mathrm{KH}-1783$ & S. sonnei & $\mathrm{Sxt}^{\mathrm{r}}, \mathrm{Nal}^{\mathrm{s}}, \mathrm{Amp}^{\mathrm{r}}, \mathrm{Cip}^{\mathrm{s}}, \mathrm{Mec}^{\mathrm{s}}$ \\
$\mathrm{KH}-1810$ & S. boydii 12 & $\mathrm{Sxt}^{\mathrm{r}}, \mathrm{Nal}^{\mathrm{r}}, \mathrm{Amp}^{\mathrm{r}}, \mathrm{Cip}^{\mathrm{s}}, \mathrm{Mec}^{\mathrm{s}}$ \\
\hline
\end{tabular}

Note: $\mathrm{S}=$ Sensitive, $\mathrm{R}=$ Resistant, $\quad \mathrm{Sxt}=$ Trimethoprim/Sulfamethoxazole, $\mathrm{Nal}=$ Nalidixic acid, Amp=Ampicillin, $\mathrm{Cip}=$ Ciprofloxacin, $\mathrm{Mec}=$ Mecillinam .

\section{Discussion}

This study has investigated the effectiveness of identification of Shigella species between conventional culture methods and PCR based methods. In order to perform a rapid and definite diagnosis of Shigella infection in patients, PCR assay is highly efficient and specific for identification of Shigella spp. using ipa $\mathrm{H}$ gene from fecal samples [2]. Therefore, the present study suggested that the detection of Shigella spp. by PCR using ipa $\mathrm{H}$ gene was higher than the existing culture plate method as well as specifically and exclusively identifies organisms that possess this gene. However, sometimes PCR can identify the genetic material of deceased organisms as well. However, in this investigation, 14 culture negative and ipa $\mathrm{H}$ positive stool samples were analysed using colony patch technique. Among them, 6 samples were identified as Shigella species and one as novel S. Dysenteriae KIVI 156. Unfortunately, no Shigella species could be identified from the remaining 7 samples of $i p a \mathrm{H}$ positive colonies. The possible reason might be accidental contamination or may be due to the presence of lactose fermenting EIEC, since lactose fermenting EIEC also possess $i p a \mathrm{H}$ gene. It is significant to note that we used only non-lactose-fermenting colonies incase of colony patch technique. In some cases, DNA from dead bacteria present in stool eventually renders a false positive result for the 
detection of Shigella. It is also evident that plasmid analysis (core plasmid) can be used as a diagnostic tool as well as 140MDa plasmid could be a diagnostic marker (in case of invasive organism) for the detection of existing Shigella as well as their new variants [12]. Several studies revealed that plasmid profile analysis is considered to differentiate strains to strains as an efficient tool in epidemiological studies dealing with enteric infections [12]. Therefore, further study will be required in details regarding plasmid extraction and analysis of the organisms isolated from the enriched culture negative and ipaH positive stool samples. All these strains were further characterized utilizing various phenotypic tools, such as, morphological characteristics, biochemical properties and antigenic features. All strains were non-lactose fermenting colonies resembling Shigella, which were discriminated from other non-lactose fermenting enteropathogenic strains by typical reaction to differentiate by demonstrating hydrogen sulfide production and fermentation of dextrose and lactose, on the basis of motility, urease and indole production and for citrate utilization (Table 1) according to the procedure described elsewhere [7]. All strains showed typical biochemical characteristics of Shigella species and confirmed by serotyping. Antibiogram analysis revealed that all strains were sensitive to ciprofloxacin as well as mecillinam, where both of the antibiotics were commonly prescribed for treating shigellosis. Therefore, this study also suggested that shigellosis patients could be treated with ciprofloxacin and mecillinam.

\section{Conclusion}

This study was designed to analyze the hidden cases (disease positive, but Shigella negative by conventional culture methods) by using molecular fingerprinting tool as PCR. Furthermore, the combination of traditional culture method with molecular fingerprinting tools will be beneficial to identify the actual disease burden due to the infection with causative agents of Shigellosis, which will be conducted for proper treatment along with further protection through improved precaution.

\section{Conflict of Interest}

The authors declare no conflict of interest.

\section{Acknowledgements}

The research protocol was funded by the Swedish International Development Cooperation Agency (Sida), grant no. MD-90020 and GR-900599. icddr,b also gratefully acknowledges the following donors who provide unrestricted support to the Centre's research efforts: Australian Agency for International Development (AusAID), Government of the People's Republic of Bangladesh, Canadian International Development Agency (CIDA), Swedish International Development Cooperation Agency (Sida), Swiss Agency for Development and Cooperation (SDC), and Department for International Development, UK (DFID).

\section{References}

[1] Holt KE et al. The HC, Thanh DP, (2016). The genomic signatures of Shigella evolution, adaptation and geographical spread. Nat Rev Microbiol Vol: 14 (4), P: 235.

[2] Thiem VD, Sethabutr O, Von Seidlein L et al.(2004) Detection of Shigella by a PCR assay targeting the ipa $\mathrm{H}$ gene suggests increased prevalence of shigellosis in NhaTrang, Vietnam. $J$ ClinMicrobiol; Vol: 42 (5), P: 2031-5.

[3] Van den Beld MJ and Reubsaet FA.(2012) Differentiation between Shigella, enteroinvasive Escherichia coli (EIEC) and non-invasive Escherichia coli. EuropeanJ ClinMicrobiolInfec Dis; Vol: 31 (6), P: 899-904.

[4] Khan A, Huq S, Talukder KA et al (2005) A. Presumptive shigellosis: clinical and laboratory characteristics of Bangladeshi patients. Scand J Infect Dis. Vol. 37, P: 96-100

[5] Talukder KA, Islam MA, Dutta DK et al.(2002) Phenotypic and genotypic characterization of serologically atypical strains of Shigella flexneri type 4 isolated in Dhaka, Bangladesh. $J$ ClinMicrobiol, Vol: 40 (7), P: 2490-7.

[6] World Health Organization, Programme for control of diarrheal disease. (1987) In Manual for laboratory investigation of acute enteric infections. Geneva,Switzerland: World Health Organization. 9-20 p.

[7] Vargas, M., J. Gascon, et al.(1999). Prevalence of Shigellaenterotoxin 1 and 2 among Shigellastrains isolated from patients with traveler's diarrhea. J. Clin. Microbiol. Vol: 37, P: 3608-3611.

[8] Talukder KA, Mondol AS, Islam MA et al.(2005) A novel serovar of Shigelladysenteriae from patients with diarrhoea in Bangladesh. J Med Microbiol. Vol: 56, P: 654-658.

[9] Ewing. W. H. \& Lindberg,(1984) A. A. Serology of Shigella. Methods Microbiol Vol: 14, P: 113-114.

[10] Wayne, PA, Performance standards for antimicrobial susceptibility testing: 20th informational supplement.(June 2010 update) Clinical and Laboratory Standards Institute, M100-S20-U.

[11] Tacket CO, Shahid N, Huq MI et al.(1984) Usefulness of plasmid profiles for differentiation of shigella isolates in Bangladesh. J ClinMicrobiol,; Vol: 20 (2), P: 300-1. 